\title{
Vibration Failure Analysis and Countermeasures of the Inlet Pipelines at a Gas Compressor Station
}

\author{
Shuangshuang Li $\mathbb{D}^{1},{ }^{1}$ Liwen Zhang, ${ }^{2}$ and Chunyan Kong ${ }^{1}$ \\ ${ }^{1}$ School of Mechanical Engineering, Xihua University, Chengdu 610039, China \\ ${ }^{2}$ School of Architectural Engineering, Chengdu Textile College, Chengdu 611731, China \\ Correspondence should be addressed to Shuangshuang Li; 15882068051@163.com
}

Received 14 August 2019; Accepted 18 October 2019; Published 6 November 2019

Academic Editor: Stefano Manzoni

Copyright (C) 2019 Shuangshuang Li et al. This is an open access article distributed under the Creative Commons Attribution License, which permits unrestricted use, distribution, and reproduction in any medium, provided the original work is properly cited.

\begin{abstract}
A gas compressor station only had its about 35\% design processing capacity as a result of the abnormal piping vibrations on the inlet pipelines. Characterization, diagnostics, analysis, and elimination of piping vibration were performed. The root causes and sources of the abnormal vibration were investigated by on-site measurements and analysis of vibration and pulsation under various load conditions of compressors. The results revealed that it was not mechanical resonance, but the high pressure pulsation and acoustic resonance occurred on the inlet pipelines, which resulted in the severe vibration. Three different modification models against vibration were proposed by shortening the length of the pipe to avoid acoustic resonance, enlarging the volume of the gathering manifold to buffer pressure pulsation, and adding supports to increase the stiffness. A better modification model was applied by performing modal analysis and fluid-structure interaction (FSI) vibration analysis using the finite element method. The effect of countermeasures was evaluated by vibration and pulsation measurements during operation after modifications, which results showed the level of piping vibration and pressure pulsation was within the allowable limits. The processing capacity of the gas station has reached its design requirement as a result of the desired reduction in vibrations.
\end{abstract}

\section{Introduction}

Reciprocating compressors are most commonly used because of their flexibility with regard to operating modes in the gas industry. However, due to the intermittent compressor suction and discharge, pipeline vibration induced by pressure pulsation in the piping system connected to the reciprocating compressor is inherent, which may result in damage of pipes, supports, foundations, and instruments, unstable process operation, malfunction of instruments, etc. Excessive piping vibration is a potential threat to the safety and reliability of the compressor system. Consequently, it is important to study and then analyze the vibration phenomena to avoid such possible problems.

The researches concerning piping vibration and vibration control mainly include vibration theoretical studies and applications in engineering [1-3]. Theoretical studies include building mathematical modeling of pipelines, vibration experiments, and investigation using numerical analysis, such as modal analysis, acoustic analysis, and fluid-structure interaction between pipe and fluid in pipe [4-6]. The acoustic wave theory, transfer matrix method, and finite element method have been proposed to analyze gas pulsation in the piping system [7, 8]. Engineering applications mainly focus on vibration measurement techniques, investigation using simulation techniques, vibration analysis techniques, fault diagnosis technology, piping design, and vibration control solutions [9-13]. These researches have laid a good foundation for the piping vibration analysis and control of compressor piping systems.

As the inlet pipelines at a gas compressor station suffered from excessive vibration, this paper was devoted to investigate the main causes and the elimination of the vibration problem. The root causes and sources of piping vibration were investigated by vibration measurements and pulsation analysis under the various load conditions of compressors. Three models of the inlet pipeline modifications based on countermeasures against vibration were 
proposed. A modification model was applied after accomplishing modal analysis and fluid-structure interaction (FSI) vibration analysis for the three models. The effect of countermeasures applied was evaluated by vibration and pulsation measurements after modifications.

\section{Vibration Problems and Cause Analysis}

2.1. Vibration Problems. A gas compressor station with a total design processing capacity of $183 \times 10^{4} \mathrm{~m}^{3} / \mathrm{d}$ employed three reciprocating compressors (No. 1 No. 3 ) with a rated power of $1250 \mathrm{~kW}$ and a capacity of $64 \times 10^{4} \mathrm{~m}^{3} / \mathrm{d}$ each and one compressor (No. 4) with a rated power of $1030 \mathrm{~kW}$ and a capacity of $55 \times 10^{4} \mathrm{~m}^{3} / \mathrm{d}$. Three of the four compressors were needed to be in operation simultaneously to meet the design processing capacity. The schematic of the inlet pipelines for the four compressors is illustrated in Figure 1. To control the piping vibration, the gathering manifold was reinforced by pouring cement, and pipe clamps were installed on the inlet pipelines during construction, as shown in Figure 2 [14].

However, the inlet pipelines encountered severe vibration with $34.26 \mathrm{~mm} / \mathrm{s}$ velocity when three compressors (No. $1 \sim$ No. 3) were in operation simultaneously during commissioning and trial operation, which was considered to be dangerous and can cause damage to the piping system. It was necessary to suppress the resulting vibration velocity to values less than $17.8 \mathrm{~mm} / \mathrm{s}$ to ensure the safety and reliability of the compressor station, according to the standard ISO 10816-6. Worse still, only one compressor was allowed to run in order to ensure pipeline safety. In other words, the compressor station only operated at its about 35\% design capacity. Hence, it was necessary to perform in depth vibration analysis to identity the root causes and sources of piping vibration and take practical and useful vibration reduction countermeasures to limit the vibration level of the inlet pipelines within the allowable range and improve the processing capacity of the compressor station.

\subsection{On-Site Measurements and Analysis}

2.2.1. Vibration Measurements and Analysis. It is a good way to understand vibration characteristics of the pipe by vibration measurements. As the vibration of the pipe connected to the reciprocating compressor is generally a low frequency vibration, vibration velocity can be used to evaluate the vibration characteristics well. Here, the total velocity of vibration $v_{\text {Total }}$ is defined to indicate the severity of piping vibration, which is calculated by

$$
v_{\text {Total }}=\sqrt{v_{x}^{2}+v_{y}^{2}+v_{z}^{2}}
$$

where $v_{\text {Total }}$ is the total velocity of vibration $(\mathrm{mm} / \mathrm{s})$ and $v_{x}$, $v_{y}$, and $v_{z}$ are the velocity of vibration in $x, y$, and $z$ directions $(\mathrm{mm} / \mathrm{s})$, respectively.

As vibration is sensitive to the speed and load conditions of the compressor, vibration measurements and analysis under different operating conditions were performed to study how the pipeline system responds to the changes in the

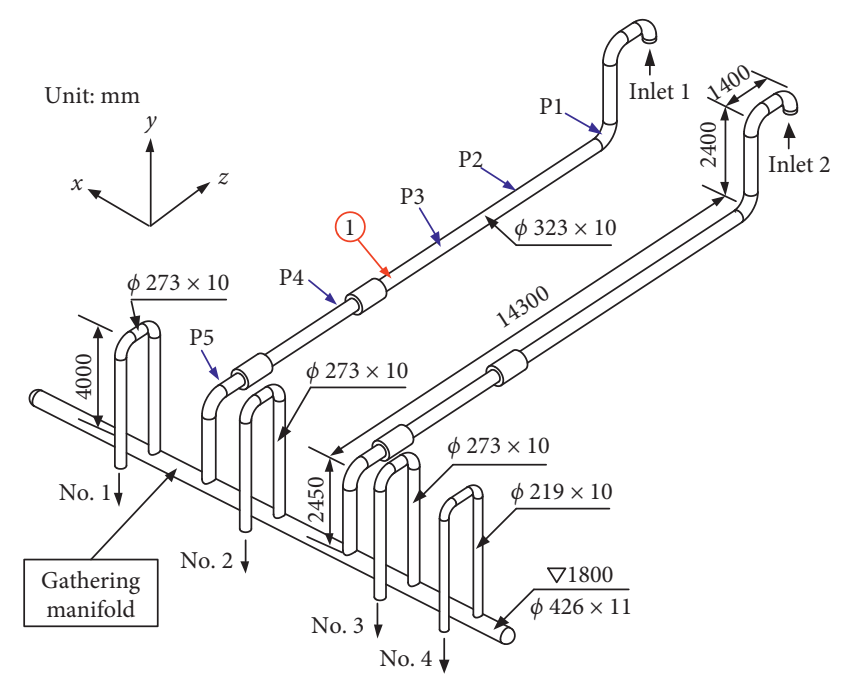

FIgURE 1: Schematic of the inlet pipelines at a gas compressor station.

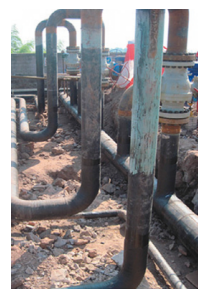

(a)

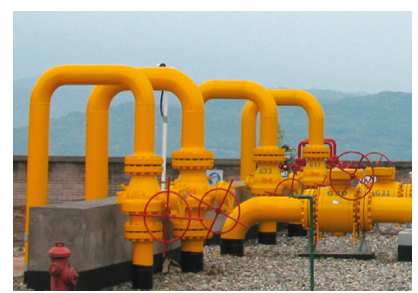

(c)

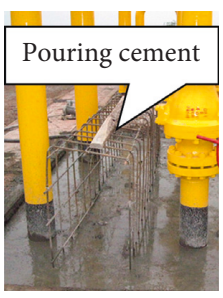

(b)
FIgURE 2: The inlet pipelines after pouring cement and installing supports during construction.

conditions. No. 1 compressor had four different load conditions, which were at 950 RPM with full load, 1000 RPM with full load, 1050 RPM with full load, and 1050 RPM with idle load, respectively. The five vibration measuring points (P1-P5) are presented in Figure 1. The comparison of vibration velocity of P1-P5 under the four load conditions is shown in Figure 3. The vibration severity is weak under No. 1 compressor operating at 1050 RPM with idle load condition, but strong under its other load conditions. So, it can be concluded that piping vibration is not induced by mechanical resonance. The total velocity of vibration $v_{\text {Total }}$ for each measuring point increases with the speed or load of No. 1 compressor. The velocity in the $z$ direction is usually greater than that in the $x$ and $y$ directions, which is due to the high pulsation forces acting on the pipe resulting from pressure and velocity fluctuations without mechanical resonance. 


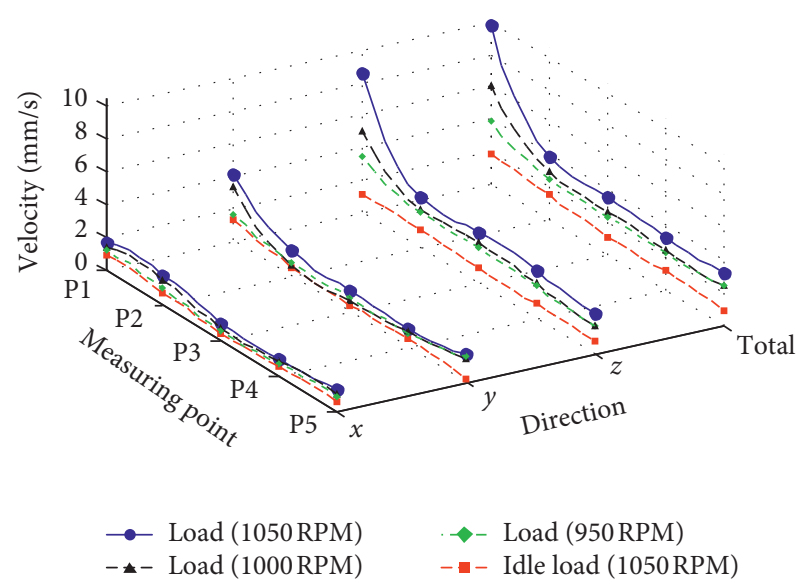

Figure 3: Comparison of velocity of P1-P5 when No. 1 compressor ran alone.

Meanwhile, the vibration velocity spectrum of P1 was analyzed to reveal the vibration level as a function of frequency, and the obtained results are plotted in Figure 4. No. 1 compressor operating at 1050 RPM would produce the fundamental frequency at $17.5 \mathrm{~Hz}$. As shown in Figure 4(a), the velocity peak occurs at $17.5 \mathrm{~Hz}$ (1050 RPM), lower velocity peaks are observed at $35 \mathrm{~Hz}$ and $52.5 \mathrm{~Hz}$, and the velocity is small or zero at other frequencies in each direction. From Figure 4(b), the velocity peak in the $z$ direction still occurs at the fundamental frequency of compressor speed and increases with the increase in the compressor speed. The spectrum results of the other points (P2-P5) are similar to that of $\mathrm{P} 1$. These spectrum characteristics are closely related to the acoustic resonance problem.

\subsubsection{Pulsation Measurements and Acoustic Analysis.} Pressure pulsation is inevitable in the reciprocating compressor because of the intermittent suction/discharge flow. The resulting pressure pulsation contains many harmonic components of the compressor speed, which would be a source of low frequency vibration in the piping system. The severity of pressure pulsation can be evaluated by the pressure unevenness $\delta$, which is calculated by equation (2). API 618 has recommended the maximum allowable level of pressure pulsation $P_{1}$, which is acquired by equation (3).

$$
\begin{aligned}
\delta & =\frac{P_{\max }-P_{\min }}{(1 / 2)\left[P_{\max }+P_{\min }\right]}=\frac{\Delta P}{P_{0}}, \\
P_{1} & =\sqrt{\frac{a}{350}} \times \frac{126.5}{\sqrt{P_{0} \times D_{1} \times f_{\mathrm{ex}}}},
\end{aligned}
$$

where $\delta$ is the pressure unevenness (\%), $P_{\max }$ and $P_{\min }$ are the maximum and minimum absolute pressure $(\mathrm{MPa})$, respectively, $P_{0}$ is the mean absolute pressure $(\mathrm{MPa})$, and $\Delta P$ is the peak-to-peak pressure $(\mathrm{MPa}), P_{1}$ is the maximum allowable level of pressure pulsation (\%), $a$ is the sound speed of gas in the pipe $(\mathrm{m} / \mathrm{s}), D_{1}$ is the inner diameter of the pipe $(\mathrm{mm})$, and $f_{\mathrm{ex}}$ is the excitation frequency related to compressor rotational speed $(\mathrm{Hz})$.
To determine the pressure pulsation level, pressure pulsation measurement at measuring point (1) (see Figure 1) was conducted when No. 1 compressor was in operation at 1050 RPM with full load. From Figure 5(a), the pressure unevenness $\delta$ of point (1) is $2.59 \%$ calculated by equation (2), which far exceeds the maximum allowable level being $0.91 \%$ acquired by equation (3). The pulsation is strongest at the first compressor harmonics $17.5 \mathrm{~Hz}$ (1050 RPM), but spikes at other harmonics exist as well, which is most likely induced by acoustic resonance.

Gas in the piping system can be considered an elastic system and also has its acoustic natural frequency. The acoustic frequency of gas depends on its sound speed in the pipe and pipe length. Gas pulsation is generally too weak to cause any problem, but may be amplified and induce excessive piping vibration due to acoustic resonance. When acoustic resonance occurs in the piping system, the length of pipe is called as resonant piping length " $L$," which can be determined by equation (4) $[15,16]$. The words "open" and "closed" present the boundary condition of the pipe end. The pipe connected to a large volume can be regarded as an open end, or a closed end.

$$
\left\{\begin{array}{l}
L=\left(\frac{\sqrt{k_{v} Z R_{\mathrm{g}} T}}{2 f_{\mathrm{ex}}}\right) i, \quad \text { (open-open or closed-closed), } \\
L=\left(\frac{\sqrt{k_{v} Z R_{g} T}}{4 f_{\mathrm{ex}}}\right)(2 i-1), \quad \text { (open-closed), }
\end{array}\right.
$$

where $L$ is the resonant piping length $(\mathrm{m}), k_{v}$ is the ratio of specific heat, $Z$ is the compressibility factor of real gas, $R_{\mathrm{g}}$ is the gas constant $(\mathrm{J} /(\mathrm{kg} \cdot \mathrm{K})), T$ is the absolute temperature $(\mathrm{K})$, and $i$ is the harmonic order of frequency.

The resonant piping length " $L$ " of the inlet pipelines is listed in Table 1. To avoid acoustic resonance, the length of pipe should be away from " $L$." Badly, the actual length of the inlet pipelines was $18.51 \mathrm{~m}$, which was within the range of the second resonant piping length " $L$." So, the pressure pulsation in piping reached a high level due to the second order acoustic resonance, which caused the high piping vibration.

In summary, the root causes of the excessive piping vibration were not mechanical resonance, but high pressure pulsation and the second order acoustic resonant. Meanwhile, there are several drawbacks in the configuration of the inlet pipelines (see Figure 1). For example, the gathering manifold was too small to buffer pulsation in the piping system, and the locations and directions of the inlet and outlet of the gathering manifold were unreasonable, which could aggravate pressure pulsation. It can be seen that piping vibration caused by acoustic resonances and pressure pulsation still cannot be controlled radically, although the inlet pipelines were reinforced by cement and clamps during construction, because the pulsation forces acting on the pipe cannot be reduced. 

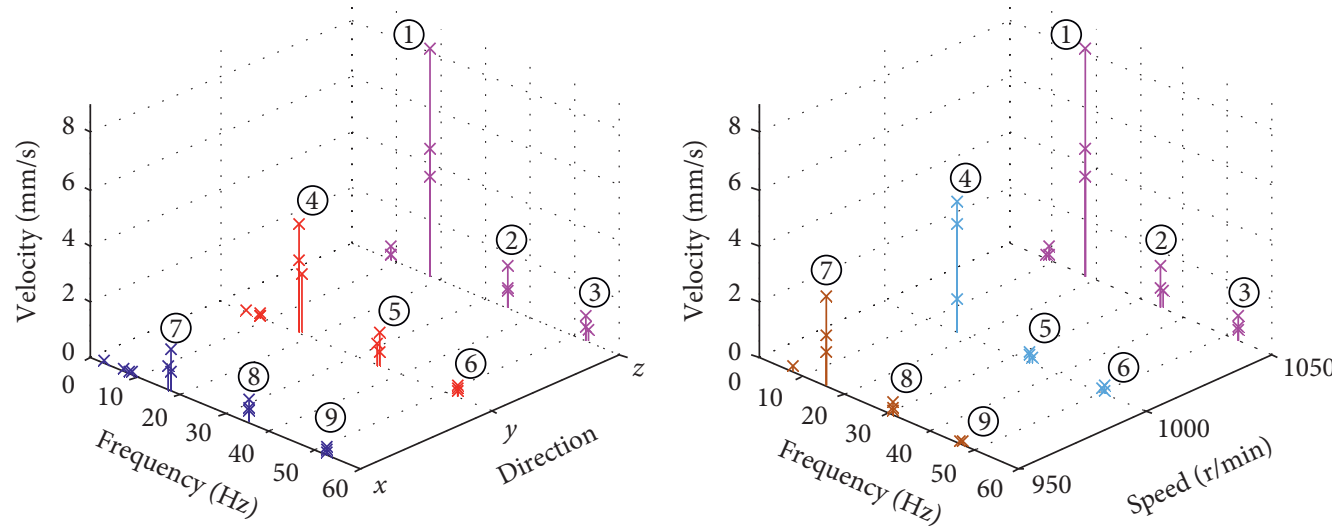

$\begin{array}{ccc} & \begin{array}{c}\text { Freq. } \\ \text { \# } \\ (\mathrm{Hz})\end{array} & \begin{array}{c}\text { Velocity } \\ (\mathrm{mm} / \mathrm{s})\end{array} \\ \text { (1) } & 17.5 & 8.11 \\ \text { (2) } & 35 & 1.52 \\ \text { (3) } & 52.5 & 0.89 \\ \text { (4) } & 17.5 & 3.93 \\ \text { (5) } & 35 & 1.2 \\ \text { (6) } & 52.5 & 0.41 \\ \text { (7) } & 17.5 & 1.41 \\ \text { (8) } & 35 & 0.838 \\ \text { (9) } & 52.5 & 0.28\end{array}$

$\begin{array}{ccc}\text { \# } & \begin{array}{c}\text { Freq. } \\ (\mathrm{Hz})\end{array} & \begin{array}{c}\text { Velocity } \\ (\mathrm{mm} / \mathrm{s})\end{array} \\ \text { (1) } & 17.5 & 8.11 \\ \text { (2) } & 35 & 1.52 \\ \text { (3) } & 52.5 & 0.89 \\ \text { (4) } & 16.875 & 4.62 \\ \text { (5) } & 33.75 & 0.39 \\ \text { (6) } & 50.625 & 0.3 \\ \text { (7) } & 15.625 & 3.165 \\ \text { (8) } & 31.25 & 0.45 \\ \text { (9) } & 46.875 & 0.1\end{array}$

(a)

(b)

FIGURE 4: The velocity spectrum of P1: (a) No. 1 compressor operating at 1050 RPM; (b) in the $z$ direction.

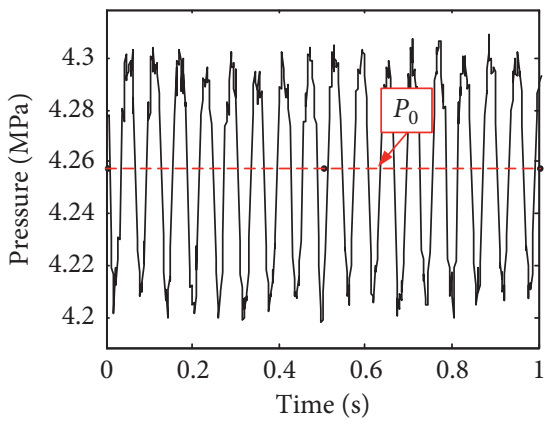

(a)

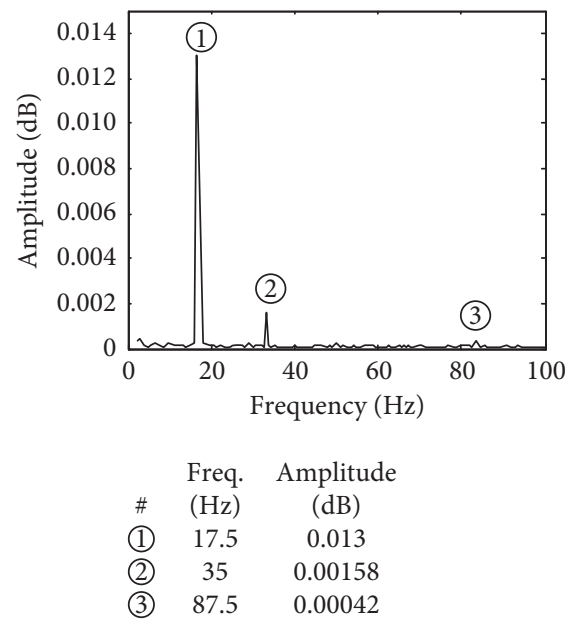

(b)

FIgURE 5: The pressure pulsation of (1): (a) pressure-time curve; (b) frequency spectrum.

TABLe 1: The first three resonant piping length " $L$ " of the inlet pipelines.

\begin{tabular}{lccc}
\hline Order & First & Second & Third \\
\hline$L(\mathrm{~m})$ & $5.93 \sim 6.55$ & $17.78 \sim 19.66$ & $29.64 \sim 32.77$ \\
\hline
\end{tabular}

\section{Countermeasures against Vibration and Analysis}

Piping vibration induced by pressure pulsation cannot be eliminated completely but can be minimized by various methods: installation of an orifice to add fluid damping, application of a pressure fluctuation absorber to reduce the pulsation itself, adjusting piping length to change the structural and acoustic resonance frequency, etc. In this study, according to the causes and sources of vibration analyzed above, the key countermeasures against vibration included shortening the length of the inlet pipelines from $18.51 \mathrm{~m}$ to $14.75 \mathrm{~m}$ to avoid the resonant piping length " $L$ " (see Table 1), enlarging the nominal diameter of the gathering manifold from DN400 $\mathrm{mm}$ to DN800 mm to suppress gas pulsation in the piping system, and adding piping 
supports to alter the natural frequency of the inlet pipelines. Three models of the inlet pipeline modifications for vibration reduction are proposed based on different processes, as shown in Figure 6.

3.1. Modal Analysis. Mechanical resonance will be induced when the excitation frequency is within $\pm 10 \%$ of the mechanical natural frequency of the piping system. Modal analysis is an effective method to obtain the natural frequencies and mode shapes of the piping system, which is of great useful to avoid mechanical resonance by adjusting the piping layout and support during the design phase. The structural models for the three models $(\mathrm{A}, \mathrm{B}$, and $\mathrm{C})$ were established from their structural drawing and physical dimensions obtained on site, which were used to predict the natural frequencies and mode shapes. The accuracy of modal analysis is highly dependent on the assumptions of the boundary conditions of the pipe. In the paper, the pipe end mounted to the equipment with a larger stiffness, such as compressor body and gathering manifold, can be defined as the fixed end. The pipe end connected to the structure with a similar stiffness can be defined as the elastic support. An elastic support or clamp can be simplified as a spring with different axial and radial stiffness. The boundary conditions and locations of supports of the three models are presented in Figure 7.

In this study, the axial stiffness of the pipe support in the $z$ direction was $k_{z}=2 \times 10^{6} \mathrm{~N} / \mathrm{m}$, and the radial stiffness of the pipe support in the $x$ direction was $k_{x}=4 \times 10^{6} \mathrm{~N} / \mathrm{m}$ and in the $y$ direction $k_{y}=2 \times 10^{7} \mathrm{~N} / \mathrm{m}$. Young's modulus $E$ and Poisson's ratio $\mu$ of the pipe were set to $206 \mathrm{GPa}$ and 0.3 , respectively. Modal analysis of the three models was performed by using the finite element method. The natural frequencies of the inlet pipelines for each model are all greater than the range of compressor excitation frequency from $15.83 \mathrm{~Hz}$ to $17.5 \mathrm{~Hz}$, as shown in Figure 8. So, the low mechanical resonance can be avoided. In terms of mechanical resonance, the first mode shape for each model is bending vibration in the $x$ direction, and the weak region with high deflection is highlighted in red in Figure 9.

3.2. Fluid-Structure Interaction Vibration Analysis. Piping vibration induced by gas pulsation in the piping system is a typical FSI vibration, which contains the structure analysis of the pipe and CFD analysis of the fluid in the piping system [17]. For the pipe connected to the natural gas compressor, the maximum allowable deformation is 710 micron based on ISO 10816-6, which is much smaller than its diameter. In this case, one-way FSI vibration analysis is appropriate because the pipe deformation is not large enough to have a significant impact on the gas pulsation. In this study, the boundary conditions of the three models for structure analysis were the same as that for modal analysis as mentioned above, and the boundary conditions for CFD analysis are listed in Table 2. The vibration level of the three models was evaluated by oneway FSI vibration analysis under the three compressors (No. $1 \sim$ No. 3) operating at 1050 RPM with full load simultaneously, and the obtained results are presented in Figure 10.

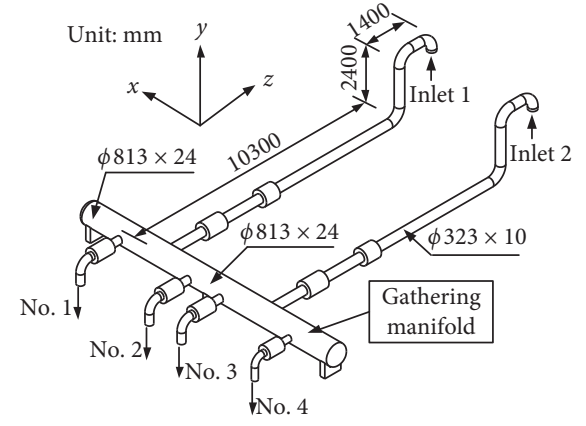

(a)

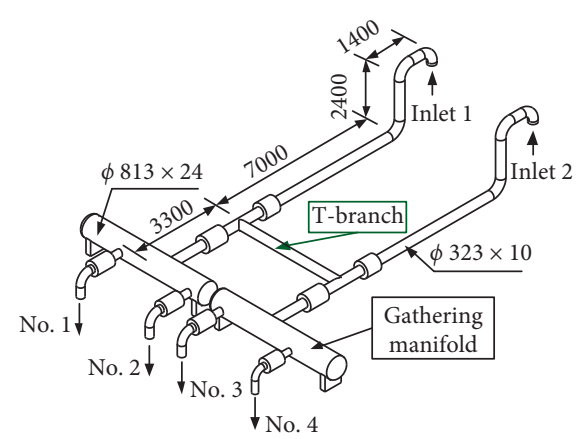

(b)

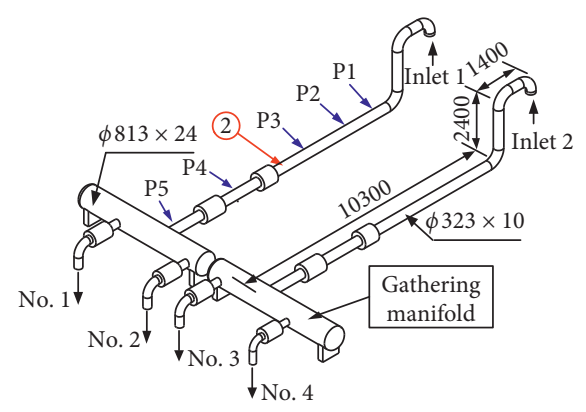

(c)

Figure 6: Three models of the inlet pipeline modifications for vibration reduction. (a) Model A: one manifold; (b) model B: two manifolds connected by T branch; (c) model C: two manifolds.

From Figure 10, the maximum vibration velocity for each modification model is less than the maximum allowable level being $17.8 \mathrm{~mm} / \mathrm{s}$. The vibration level of modification model C is lower than that of models A and B. As the high vibrations are observed at the bend of the inlet pipelines because of the insufficient stiffness of pipe supports, a support with higher stiffness should be installed during the modification phase. According to Figures 9-11, it can be concluded that the inlet pipeline modification model $\mathrm{C}$ is better than models $\mathrm{A}$ and $\mathrm{B}$ with regard to vibration suppression because it has a higher natural frequency and a lower vibration severity.

\section{Effect of Countermeasures}

The inlet pipelines were modified on the basis of the modification model $\mathrm{C}$ to mitigate the abnormal vibration (see Figure 11). Meanwhile, the weak regions in Figure 10(c) 


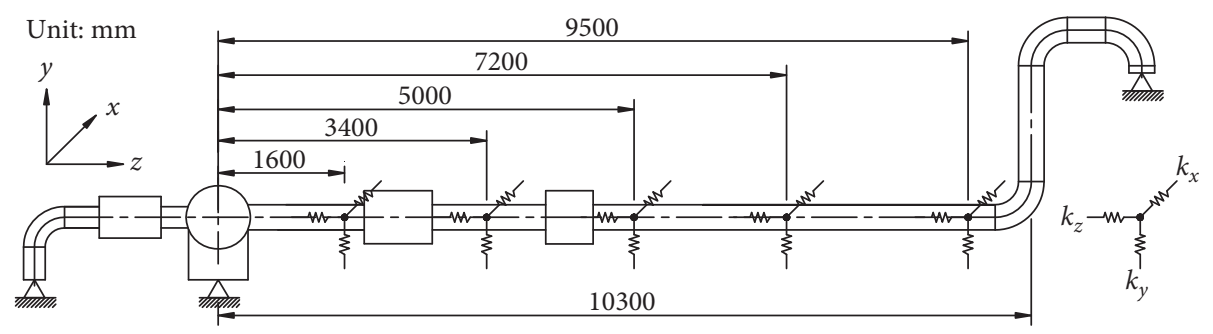

FIGURE 7: Boundary conditions and locations of supports of the inlet pipeline modifications.

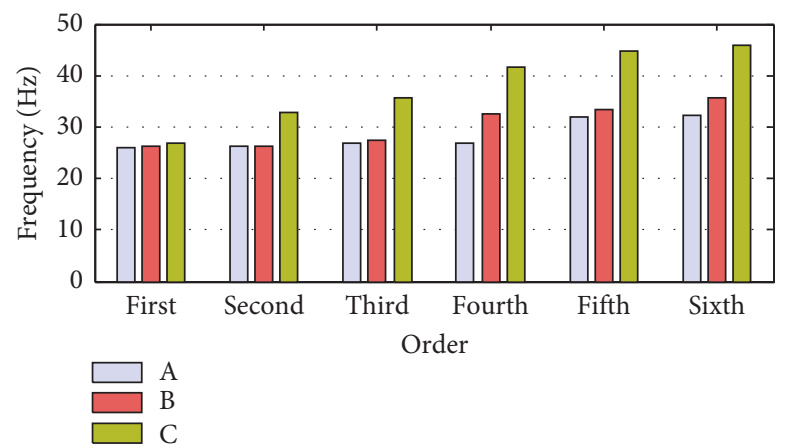

FIgURE 8: Comparison of the first six natural frequencies of the inlet pipeline modification models.

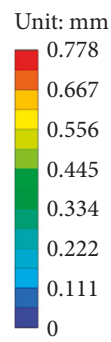

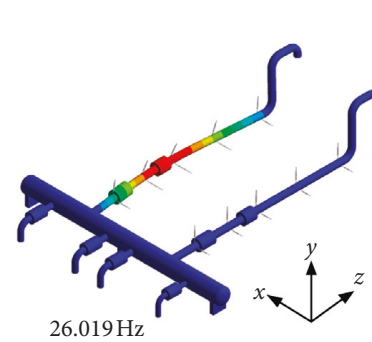

(a)

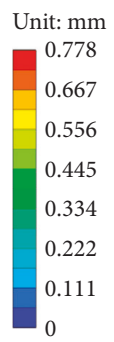

$26.179 \mathrm{~Hz}$

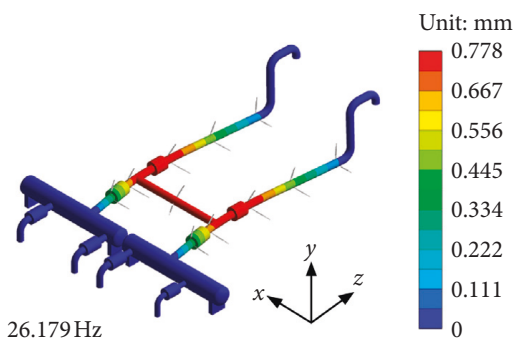

(b)

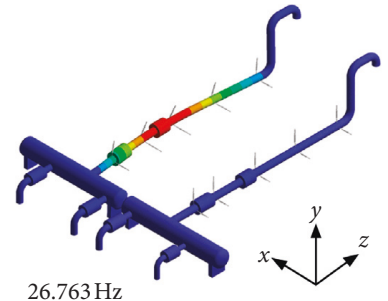

(c)

Figure 9: The first frequency and mode shape of the inlet pipeline modifications. (a) Model A; (b) model B; (c) model C.

TABLE 2: Boundary conditions of the inlet pipeline modification models for CFD analysis.

\begin{tabular}{|c|c|c|c|c|c|c|}
\hline \multirow{2}{*}{ Position } & \multicolumn{2}{|c|}{ Model A } & \multicolumn{2}{|c|}{ Model B } & \multicolumn{2}{|c|}{ Model C } \\
\hline & Boundary condition & Value & Boundary condition & Value & Boundary condition & Value \\
\hline Inlet1 & Pressure inlet & $4.2 \mathrm{MPa}$ & Pressure inlet & $4.2 \mathrm{MPa}$ & Pressure inlet & $4.2 \mathrm{MPa}$ \\
\hline Inlet2 & Wall & - & Wall & - & Pressure inlet & $4.2 \mathrm{MPa}$ \\
\hline No. 1 & Velocity outlet & $0.89 \mathrm{~m} / \mathrm{s}$ & Velocity outlet & $0.89 \mathrm{~m} / \mathrm{s}$ & Velocity outlet & $0.89 \mathrm{~m} / \mathrm{s}$ \\
\hline No. 2 & Velocity outlet & $0.89 \mathrm{~m} / \mathrm{s}$ & Velocity outlet & $0.89 \mathrm{~m} / \mathrm{s}$ & Velocity outlet & $0.89 \mathrm{~m} / \mathrm{s}$ \\
\hline No. 3 & Velocity outlet & $0.89 \mathrm{~m} / \mathrm{s}$ & Velocity outlet & $0.89 \mathrm{~m} / \mathrm{s}$ & Velocity outlet & $0.89 \mathrm{~m} / \mathrm{s}$ \\
\hline No. 4 & Wall & - & Wall & - & Wall & - \\
\hline
\end{tabular}

Velocity $0.89 \mathrm{~m} / \mathrm{s}$ is converted by $64 \times 10^{4} \mathrm{~m}^{3} / \mathrm{d}$ based on the gas equation of state and the diameter of pipe.

which were sensitive to vibration were strengthened by pipe clamps. To evaluate the effect of countermeasures after modifications, vibration measurements were completed under two different load conditions: No. 1 and No. 2 compressors operating at 1050 RPM with full load and No. 1 compressor operating at 1050 RPM with full load. The input parameters and operating conditions of the compressors were approximate to those before modifications. The vibration measuring points from $\mathrm{P} 1$ to $\mathrm{P} 5$ and pulsation measuring point (2) are illustrated in Figure 6.

As seen in Figure 12, the total vibration velocity $v_{\text {Total }}$ is reduced after modifications, especially for measuring point P1. The vibration velocity increases with the compressor load. Although the piping vibration intensity became larger when No. 1 and No. 2 compressors operated at 1050 RPM with full load, all vibration velocity was still within the limits 


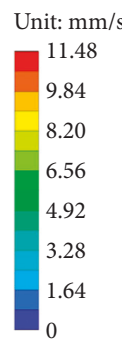

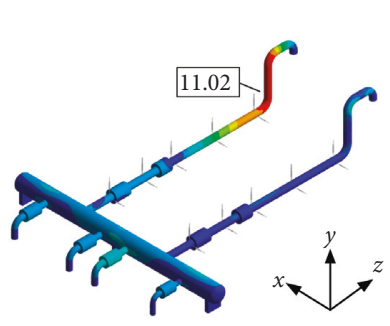

(a)

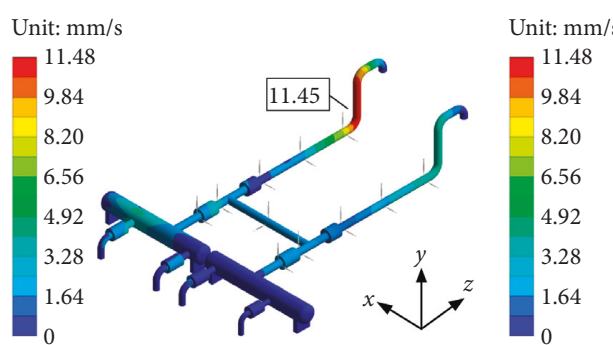

(b)

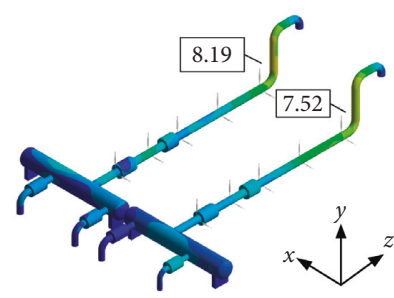

(c)

FIGURE 10: Results of vibration velocity of the inlet pipeline modification models evaluated by FSI vibration analysis. (a) Model A; (b) model B; (c) model C.

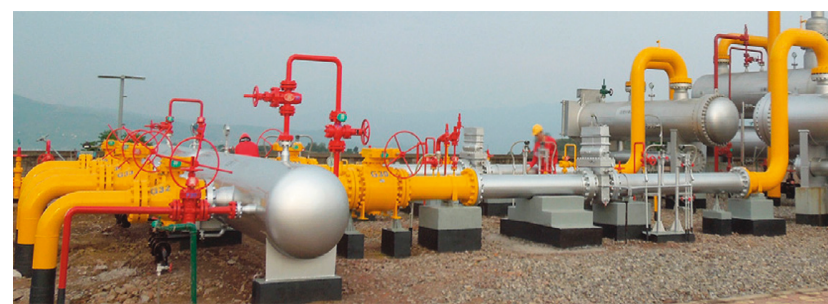

FIgURE 11: The inlet pipelines after modifications.

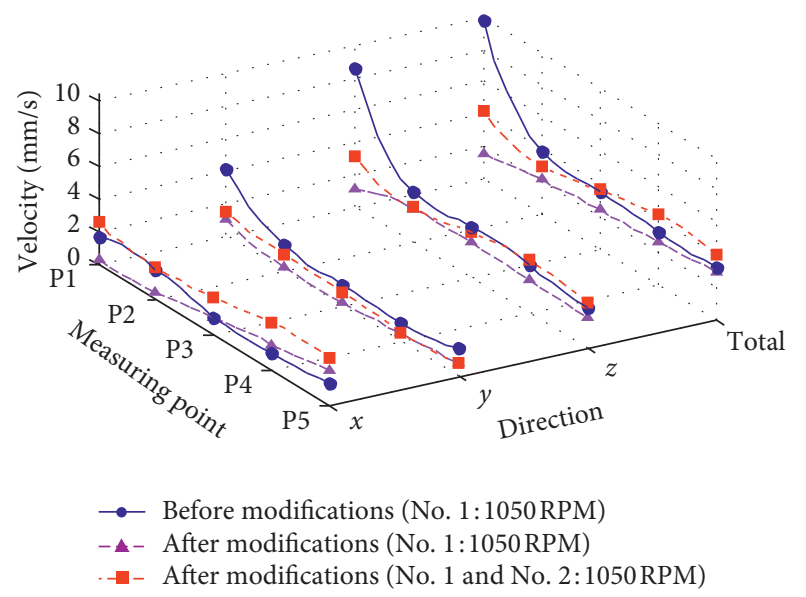

FIGURE 12: Comparison of velocity before and after modifications.

being $17.8 \mathrm{~mm} / \mathrm{s}$. Thus, any three of the four compressors can operate well at the same time without any abnormal piping vibration, and the capacity of the gas station was increased to the design processing capacity after modifications.

Pressure pulsation analysis of measuring point (2) when No. 1 and No. 2 compressors ran simultaneously was conducted after modifications, and the obtained results are presented in Figure 13. The maximum pressure unevenness of (2) is $0.63 \%$, which is limited within the maximum allowable level being $0.91 \%$. Comparing Figure 5(b) with Figure 13(b) shows that the pressure pulsation peak at $17.5 \mathrm{~Hz}$ is $0.0048 \mathrm{~dB}$ after modifications, but $0.013 \mathrm{~dB}$ before modifications. As the length of the inlet pipelines avoided the second order resonant piping length " $L$ " after modifications, the pressure pulsation was not amplified without acoustic resonance.

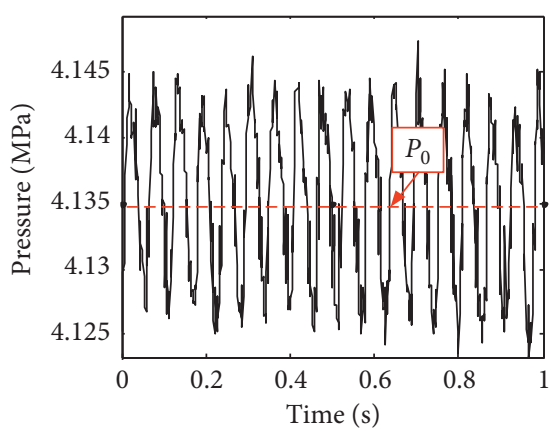

(a)

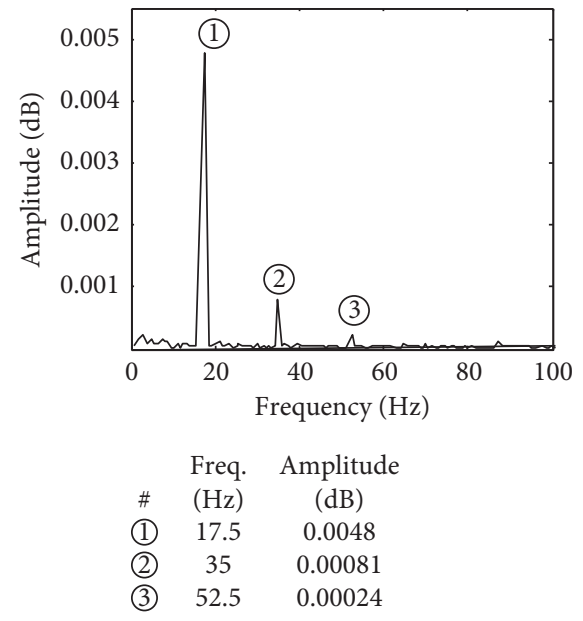

(b)

FIgURE 13: The results of pressure pulsation of (2) after modifications. (a) Pressure-time curve; (b) frequency spectrum.

\section{Conclusions}

The paper presents the characterization, diagnostics, analysis, and elimination of vibration in the inlet pipelines connected to reciprocating compressors at a gas station. The most important conclusions are as follows:

(1) The results of on-site vibration and pulsation measurements under various load conditions of compressors showed the abnormal vibration of the inlet pipelines was not induced by mechanical resonance, but the second order acoustic resonance occurred in the inlet pipelines. 
(2) Three modification models were proposed to suppress piping vibration and pressure pulsation, which mainly focused on shortening the length of pipe to avoid acoustic resonance, enlarging the volume of the gathering manifold to buffer pressure pulsation, and adding supports to increase the stiffness. Modal analysis and FSI vibration analysis for each modification model were conducted to understand their modal characteristics and vibration level, and the results revealed that the piping vibration level under the design processing capacity conditions of the compressor station was within the allowable limits without mechanical and acoustic resonance.

(3) The inlet pipelines were modified based on modification model $\mathrm{C}$ to suppress piping vibration, and the weak regions which were sensitive to vibration were strengthened by installing pipe clamps after modifications. The results showed the piping vibration and pressure pulsation level were within the acceptable limits of standard, which means the countermeasures adopted indeed eliminated the piping vibration after modifications.

Piping vibration is an inescapable reality for the piping system connected with a reciprocating compressor. Generally, vibration induced by pressure pulsation is small on a pipe without acoustic or mechanical resonance. Therefore, eliminating the acoustic or mechanical resonance can be an effective measure to reduce piping vibration.

\section{Data Availability}

Data and models used to support the findings of this study are available from the corresponding author upon request.

\section{Conflicts of Interest}

The authors declare that there are no conflicts of interest regarding the publication of this paper.

\section{Acknowledgments}

This work was supported by the Key Scientific Research Fund of Xihua University (Grant No: Z17118); the Natural Science Foundation of the Education Department of Sichuan Province (Grant No: 18ZB0574); and the Open Research Subject of Key Laboratory (Research Base) of Fluid and Power Machinery of Xihua University, Ministry of Education (Grant No: szjj2017-081).

\section{References}

[1] N. Lieberman, Troubleshooting Natural Gas Processing: Wellhead to Transmission, PennWell Publishing Company, Tulsa, OK, USA, 1987.

[2] B. Xu, Q. Feng, and X. Yu, "Prediction of pressure pulsation for the reciprocating compressor system using finite disturbance theory," Journal of Vibration and Acoustics, vol. 131, no. 3, Article ID 031007, 2009.

[3] S. K. Loh, W. F. Faris, M. Hamdi, and W. M. Chin, "Vibrational characteristics of piping system in air conditioning outdoor unit," Science China Technological Sciences, vol. 54, no. 5, pp. 1154-1168, 2011.

[4] T. Nakamura, S. Kaneko, F. Inada et al., Flow-Induced Vibrations: Classifications and Lessons from Practical Experiences, Butterworth-Heinemann, Oxford, UK, 2013.

[5] G. Liu, S. Li, Y. Li, and H. Chen, "Vibration analysis of pipelines with arbitrary branches by absorbing transfer matrix method," Journal of Sound and Vibration, vol. 332, no. 24, pp. 6519-6536, 2013.

[6] S. Li, B. W. Karney, and G. Liu, "FSI research in pipeline systems-a review of the literature," Journal of Fluids and Structures, vol. 57, pp. 277-297, 2015.

[7] B. Liu, J. Feng, Z. Wang, and X. Peng, "Attenuation of gas pulsation in a reciprocating compressor piping system by using a volume-choke-volume filter," Journal of Vibration and Acoustics, vol. 134, no. 5, Article ID 051002, 2012.

[8] F. Trebuňa, F. Šimčák, R. Huňady, and M. Pástor, "Identification of pipes damages on gas compressor stations by modal analysis methods," Engineering Failure Analysis, vol. 27, pp. 213-224, 2013.

[9] S.-H. Lee, S.-M. Ryu, and W.-B. Jeong, "Vibration analysis of compressor piping system with fluid pulsation," Journal of Mechanical Science and Technology, vol. 26, no. 12, pp. 3903-3909, 2012.

[10] H. Ashrafizadeh, M. Karimi, and F. Ashrafizadeh, "Failure analysis of a high pressure natural gas pipe under split tee by computer simulations and metallurgical assessment," Engineering Failure Analysis, vol. 32, pp. 188-201, 2013.

[11] H. G. Varghese, M. Saad Ahamed, and K. Srikanth, "Pipeline vibration reduction in reciprocating compressors," International Journal of Innovation and Applied Studies, vol. 6, no. 3, p. 629, 2014.

[12] I. Hayashi and S. Kaneko, "Pressure pulsations in piping system excited by a centrifugal turbomachinery taking the damping characteristics into consideration," Journal of Fluids and Structures, vol. 45, pp. 216-234, 2014.

[13] M. Udagawa, Y. Li, A. Nishida, and I. Nakamura, "Failure behavior analyses of piping system under dynamic seismic loading," International Journal of Pressure Vessels and Piping, vol. 167, pp. 2-10, 2018.

[14] Z. Liang, S. Li, J. Tian, L. Zhang, C. Feng, and L. Zhang, "Vibration cause analysis and elimination of reciprocating compressor inlet pipelines," Engineering Failure Analysis, vol. 48, pp. 272-282, 2015.

[15] P. Cyklis, "Experimental identification of the transmittance matrix for any element of the pulsating gas manifold," Journal of Sound and Vibration, vol. 244, no. 5, pp. 859-870, 2001.

[16] Y. Zhao, B. Zhao, Q. Zhou, X. Jia, J. Feng, and X. Peng, Analysis and Control of Severe Vibration of a Screw Compressor Outlet Piping System, Purdue University Purdue e-Pubs, West Lafayette, Indiana, 2016.

[17] M. Siba, W. Wanmahmood, M. Z. Nuawi, R. Rasani, and M. Nassir, "Flow-Induced vibration in pipes: challenges and solutions-a review," Journal of Engineering Science and Technology, vol. 11, no. 3, pp. 362-382, 2016. 


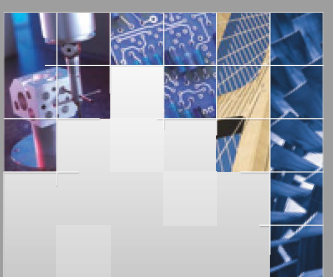

\section{Enfincering}
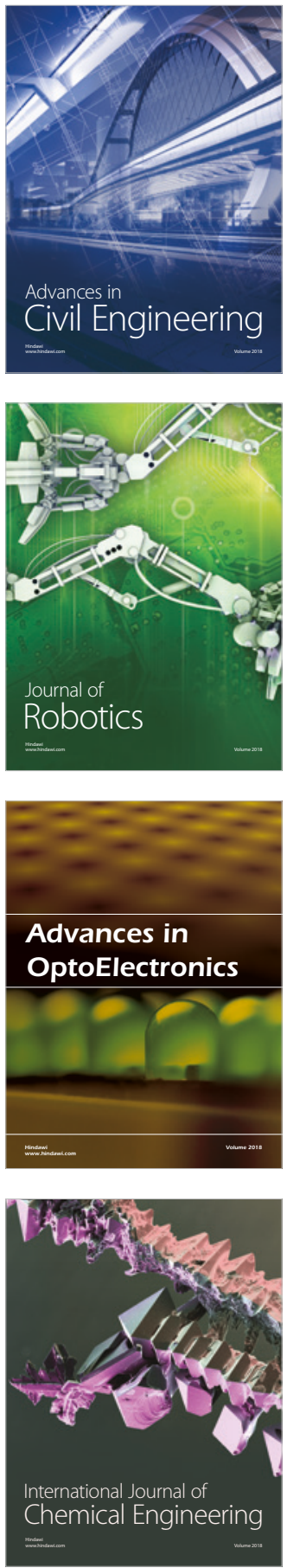

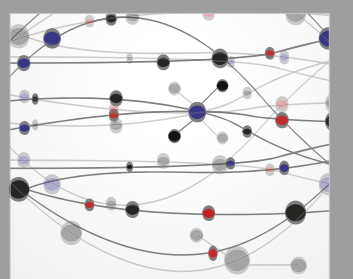

\section{Rotating \\ Machinery}

The Scientific World Journal

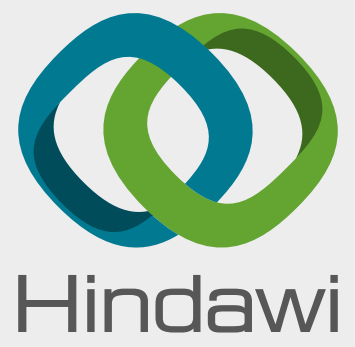

Submit your manuscripts at

www.hindawi.com
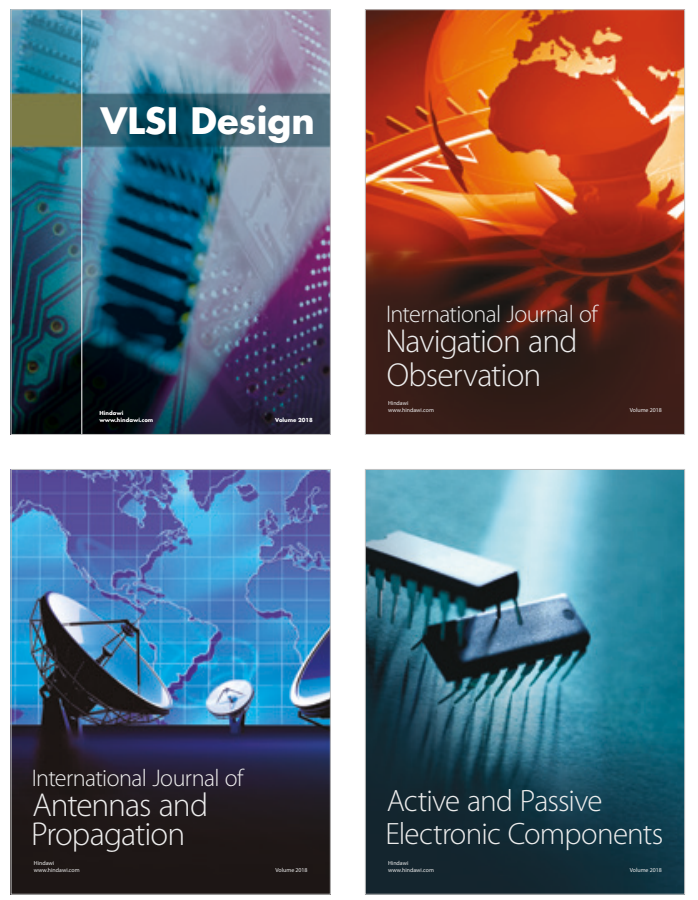
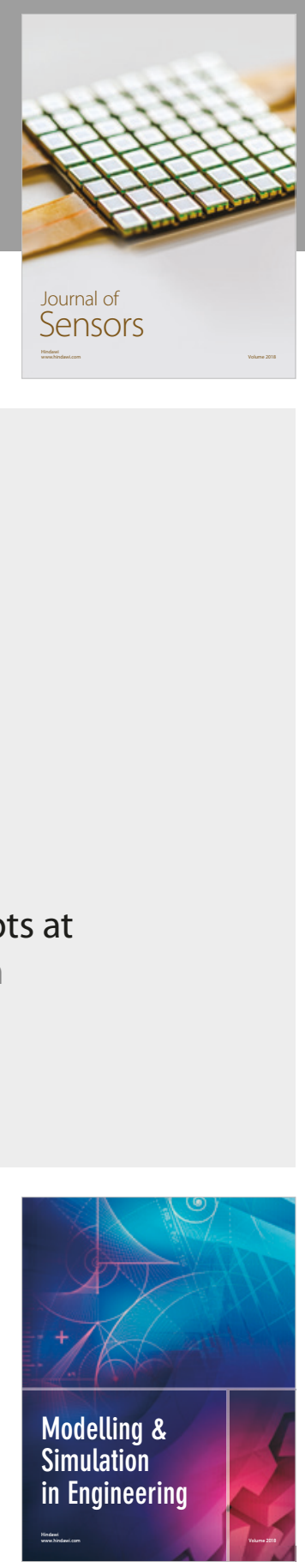

\section{Advances \\ Multimedia}
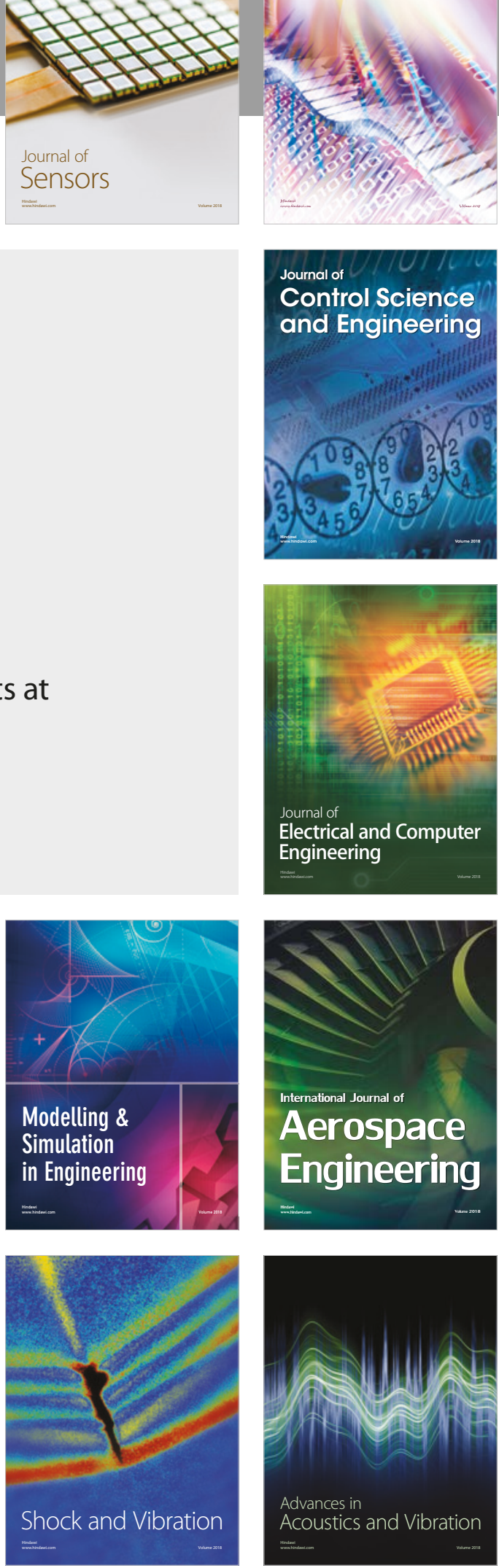